\title{
Investigation of stress-state in rolled sheets by ultrasonic techniques
}

\author{
Y. Ivanova ${ }^{1}$, T. Partalin ${ }^{2}$ \\ Institute of Mechanics-Bulgarian Academy of Sciences ${ }^{l}$, Sofia University ${ }^{2}$, Bulgaria \\ ${ }^{1}$ Acad.G.Bonchev Str.Bl.4, Sofia,1113,BULGARIA,E-mail:yonka@imbm.bas.bg ${ }^{1}$,topart@fmi.uni-sofia.bg ${ }^{2}$
}

\begin{abstract}
The present paper concerns investigation of the stress-state in materials by ultrasonic technique. The velocities of ultrasonic surface waves are measured in different directions on the surface of rolled steel sheets. The signal processing and cross spectra methods are used to study the stress in a steel sample.
\end{abstract}

Keywords: ultrasonic surface waves, anisotropy, velocity, mechanical stress

\section{Introduction}

Propagation of ultrasonic waves depends on physical properties of the medium, the volume density and the stress state [1-2]. Measurements of the change in stressinduced ultrasonic bulk and surface wave velocities give the necessary information for stress evaluation [1-10]. The investigations on the acoustoelasticity by the Rayleigh wave in the non-uniform stress state the first time were provided in [5] and extended in [6-8]. Numerical and experimental results of the longitudinal and linearly polarized shear ultrasonic impulses that propagate in a material subjected to bending are presented in [9]. The acoustoelastic measurements have been realized in [10] to determine mechanical and elastic properties in a compression stressed material. The experiments and modeling of the stress gradient in aluminum by surface ultrasonic waves are given in [11].

In isotropic and uniformly stressed materials the stress-induced velocity changes are defined as $[1,2,11]$

$$
\begin{aligned}
& \left(C_{R_{1}}-C_{R_{o}}\right) / C_{R_{o}}=k_{1} \sigma_{1}+k_{2} \sigma_{2}, \\
& \left(C_{R_{2}}-C_{R_{o}}\right) / C_{R_{o}}=k_{1} \sigma_{2}+k_{2} \sigma_{1},
\end{aligned}
$$

where $C_{R_{1}}$ and $C_{R_{2}}$ are the Rayleigh wave velocities in the principal stress directions, $C_{R_{o}}$ is the isotropic Rayleigh wave velocity, $\sigma_{1}, \sigma_{2}$ the principal stresses and $k_{1}, k_{2}$ are stress-acoustoelastic constants.

When the stress varies in the direction of depth, the Rayleigh wave will be dispersive since the depth of penetration of the Rayleigh wave is proportional to the wavelength. Consider a linear stress distribution in the direction perpendicular to the surface of the section of sample in [11]:

$$
\left(C_{R}-C_{R_{o}}\right) / C_{R_{o}}={ }_{k_{1}} \sigma_{1}+\frac{\beta}{\omega} \frac{d \sigma_{1}}{d h}
$$

where $\omega=2 \pi f$ notes the circular frequency, $\beta$ is a constant. The stress gradient $(d \sigma / d h)$ can be determined by measuring the Rayleigh wave velocity at two different frequencies.

This paper focuses on Rayleigh surface waves for detecting the stress gradient in cantilever made of carbon steel. The modeling and experiments on the propagation of ultrasonic surface waves on cantilever with a transversal and longitudinal stress gradient are carried out in [12-13]. That formulation makes the results difficult to be compared and assessed. In order to find quantitative interrelations between the stress-state of the material and surface ultrasonic waves it is necessary to create a model in which only the transversal stress gradient is significant.

The aim of the work is to find out the appropriate parameter of ultrasonic waves for stress-state evaluation of the materials with stress gradient.

The procedure of the current experiment is realized by consecutive loading of metal sheets and registration of the ultrasonic wave signal. A triangular shaped cantilever with a constant strength is subjected to bending so that the desired stress distribution is obtained. The propagation of ultrasonic surface waves in a bent metal beam is assessed depending on the stress gradient and the ratio $\lambda / h$, where $\lambda$ is the ultrasonic wavelength and $h$ is the thickness of the metal sample.

We use the following approximation accepted for some applications. The triangular in plane sample, made from low carbon steel, is loaded with force $P$ as shown in Fig. 1. The width of the beam $b(x)$ at the distance $x$ from the application point of the bending force $P$ is

$$
b(x)=2 x \tan \frac{\alpha}{2}=2 x k,
$$

where $\alpha$ is the angle at the apex of the triangular beam and $\tan \frac{\alpha}{2}=k$.

So the value of the normal stress at the surface is determined by [14]

$$
\sigma(x)=\frac{M_{y}}{W_{y}}=\frac{P x}{\frac{b(x) h^{2}}{6}}=\frac{3 P}{h^{2} k}=\sigma,
$$

where $\sigma$ is the stress, $M_{y}$ is the bending moment toward axis $y, W_{y}$ is the resistance moment. The axes $y$ and $z$ are principal axes of inertia and $x$ is the arm of the applied force $P$. Under the terms of the acceptances, the normal stress is independent of $x$. According to the scheme in Fig. 1 the part of the beam where $z$ is less than 0 is compressed and the part where $z$ is greater than zero is strained.

All the samples have the same length $(l=0.5 \mathrm{~m})$, width ( $B=0.4142 \mathrm{~m}$ ), the angle $\alpha=45^{\circ}$ or $k=0.414$ and different 
thicknesses $h(5,6,8,10 \mathrm{~mm})$. The bending loads are chosen small enough to prevent residual deformations and stresses. The stress gradient is equal to the ratio $2 \sigma / h$.

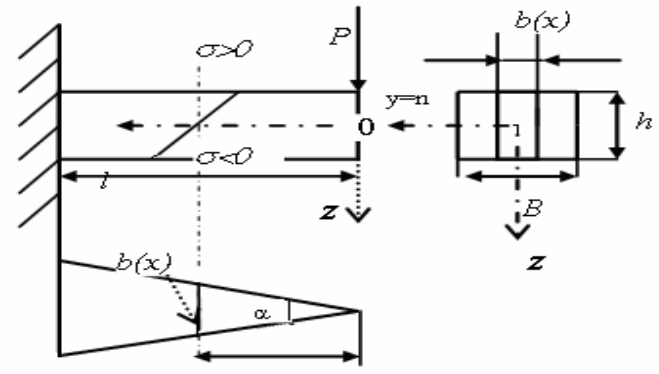

$x$

Fig.1. Scheme of bending metal sample with constant height and variable width, loaded by bending force

\section{Ultrasonic measurement}

An experimental set-up for ultrasonic investigation is shown in Fig. 2. The computerized ultrasonic instrument allows measuring the propagation time of an ultrasonic impulse with accuracy up to $1 \mathrm{~ns}$ and 8 bits resolution at the sampling rate of $100 \mathrm{MHz}$ [15].

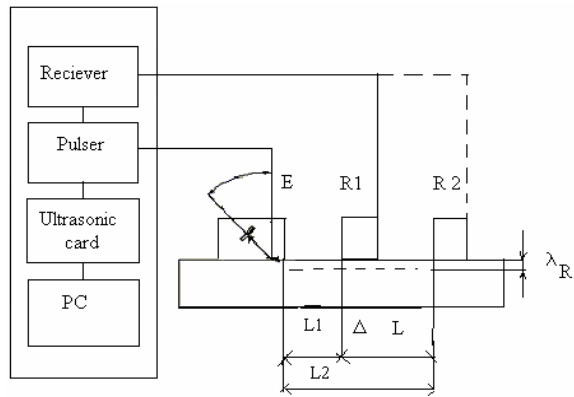

Fig.2. The experimental set-up for ultrasonic investigation by through transmission technique

The surface Rayleigh ultrasonic waves are excited by an angular transducer with a variable angle. The central frequencies of the used transducers are 2 and $4 \mathrm{MHz}$. The wavelengths are approximately $0.75 \mathrm{~mm}$ and $1.5 \mathrm{~mm}$ for the frequency $4 \mathrm{MHz}$ and $2 \mathrm{MHz}$. The propagation depths of the surface wave are of the order of $1,7 . \lambda_{R}$, i.e., $2.5 \mathrm{~mm}$ and $1.25 \mathrm{~mm}$ for $2 \mathrm{MHz}$ and $4 \mathrm{MHz}[16,17]$.

The signal is emitted by the transducer E, received by the transducer $\mathrm{R}$ and recorded as shown in Fig.3. The receiving transducer moves along the acoustic path covering the distance $\Delta L$.

The velocities of surface waves are measured for samples with varying thickness $h$ and loads till $500 \mathrm{~N}$, so the stress to be less than 50-60 MPa. The velocity of the surface wave $C_{R}$ is estimated in the following way [16].

$$
C_{R}=\frac{2(L 2-L 1)}{\tau_{2}-\tau_{1}}=\frac{\Delta L}{\Delta \tau},
$$

where $\Delta L$ is the distance between the positions $R 1$ and $R 2$ of the receiver $R, \tau_{1}, \tau_{2}$ are the arrival times of the wave obtained at the distances $L 1, L 2$ and registered from the starting point of the ultrasonic impulse. The time is the average of 16 times of flight measurements.

The distance $L 1$ is about 20 wavelengths for $2 \mathrm{MHz}$ and 40 wavelengths for $4 \mathrm{MHz}$. The distance $L 2$ is about 7 times higher. The relative change of the surface wave velocity is determined by the relation:

$$
d C_{R}=\left(C_{R}-C_{R_{o}}\right) / C_{R_{o}}
$$

where $C_{R}$ and $C_{R_{o}}$ are the velocities in stressed and unstressed media.

\section{Signal processing. Spectral analysis}

The registered signals from surface ultrasonic waves are processed as described in [17]. The procedure includes smoothing, filtering, applying a Fourier transformation and determining the spectrum [18].

The complex frequency spectrum of the signal $x(t)$ is found after performing Fourier transformation

$$
G(f)=F(x(t))=S(f) e^{-i \varphi(2 \pi f)}
$$

where $S(f)$ is the amplitude and $\phi(f)$ is phase spectra:

$$
\begin{gathered}
S(f)=|G(f)|=\sqrt{[\operatorname{Re} G(f)]^{2}+[\operatorname{Im} G(f)]^{2}}, \\
\phi(f)=\arg G(f)=\operatorname{arctg}\left(\frac{\operatorname{Im} G(f)}{\operatorname{Re} G(f)}\right) .
\end{gathered}
$$

\section{Cross-spectrum analysis}

To assess the difference between the signals from unstressed samples and these ones with mechanical stresses, we use a cross-spectrum analysis [18-22]. This processing technique is applied to the signals obtained for one and the same distance and shifted with respect to the time of arrival.

The cross-spectrum of the signals $x(t), y(t)$ is found as follows [19]:

$$
C S_{x y}(f)=G_{x}(f) G_{y}^{*}(f)
$$

where $G_{x}(f)$ and $G_{y}(f)$ are the Fourier images of $x(t)$, $y(t)$ respectively and $G_{y} *(f)$ is complex-conjugated to $G_{y}(f)$. The phase $\Phi_{x y}$ of the cross-spectrum $C S_{x y}(f)$ of the studied signals in the specified frequency range measures the phase lag. The time delay is represented by the slope of the phase spectrum [18-20]:

$$
\Phi_{x y}(f)=\operatorname{arctg}\left(\frac{\operatorname{Im}\left(C S_{x y}(f)\right)}{\operatorname{Re}\left(C S_{x y}(f)\right)}\right) .
$$

The spectrum of the signal of unstressed material $\mathrm{S}_{0}$ is correlated with the spectrum of the signal of the stressed material $S_{i}$, here $i=1,2 \ldots \mathrm{n}$ correspond to different loads and stress.

\section{Results and discussion}

The results of the bending test are shown in Fig. 3 and 4. The measurements are carried out on the tension side of the beam. The signals from ultrasonic surface waves 
before and after loading in the case when the acoustical path line is perpendicular to the bending moment are shown in Fig. 3a-d for $2 \mathrm{MHz}$ and $4 \mathrm{MHz}$. The ultrasonic impulses in stressed materials are received earlier than those in the unloaded samples and their shapes and lengths are changed.

\section{Ultrasonic velocity}

The Fig. 4 shows the dependences of the relative velocity change on the stresses at the surface of samples 5 , 8 and $10 \mathrm{~mm}$ thick.

The value $d C_{R}$ increases with the growth of the stress gradient. The results obtained at the frequencies $2 \mathrm{MHz}$ and $4 \mathrm{MHz}$ are given as a square and circle marks. The values obtained for thinner sample with maximum stress gradient (a) are higher than those for the samples with the thicknesses $h=8 \mathrm{~mm}$ (b) and $h=10 \mathrm{~mm}$ (c).
The $2 \mathrm{MHz}$ wave velocity is faster since it has a longer wavelength and penetrates deeper into the surface than that of $4.0 \mathrm{MHz}$ and the average stress of the affected layer is lower. The average stress depends on the ratio wavelength - thickness $(\lambda / h)$ and is determined by

$$
\sigma_{\text {aver }}=\sigma_{\max }\left(1-\gamma \frac{\lambda}{n}\right) \text {. }
$$

The value $n=h / 2$ marks the distance from the surface to the zero line, where the stress is equal to zero and $\gamma$ corresponds to the wave penetration depth. Fig.5 shows a distribution of relative velocity change in dependence of the average stress and the stress gradient. The obtained results are in good agreement with [11].
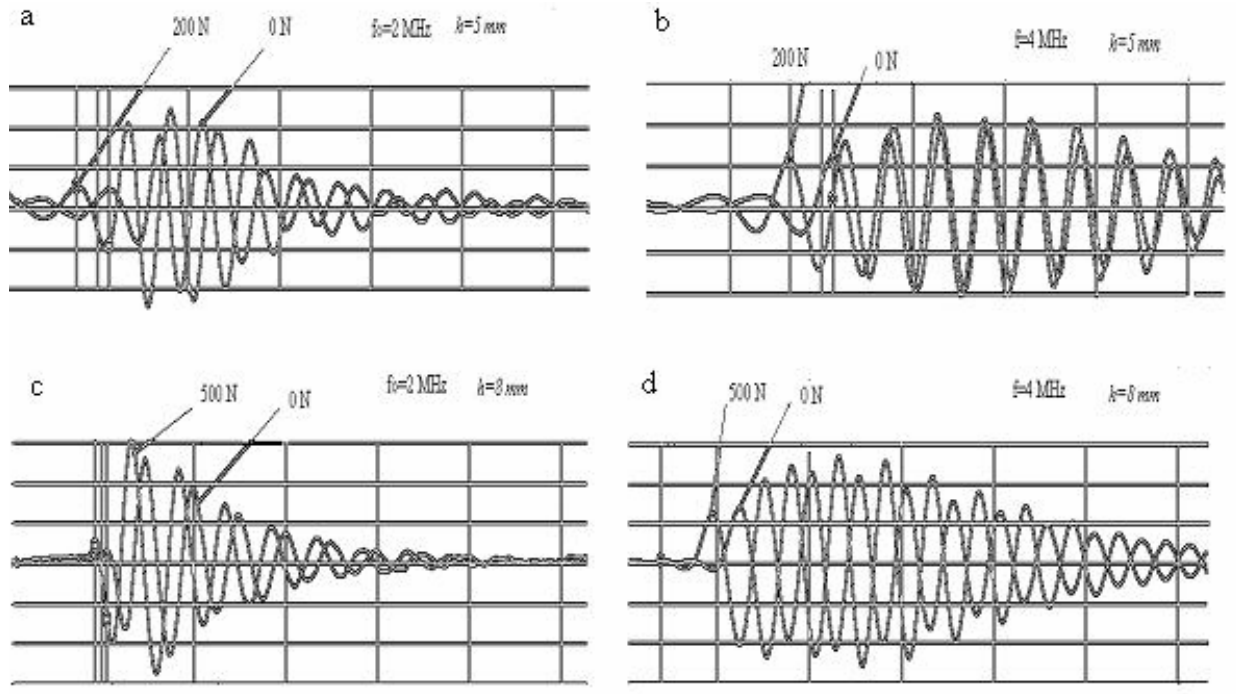

Fig.3. Signals before and after loading of the samples with $h=5 \mathrm{~mm}(\mathrm{a}, \mathrm{b})$ and $8 \mathrm{~mm}(\mathrm{c}, \mathrm{d})$

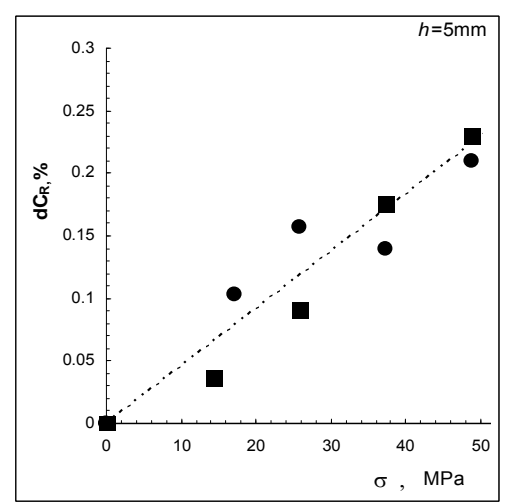

a

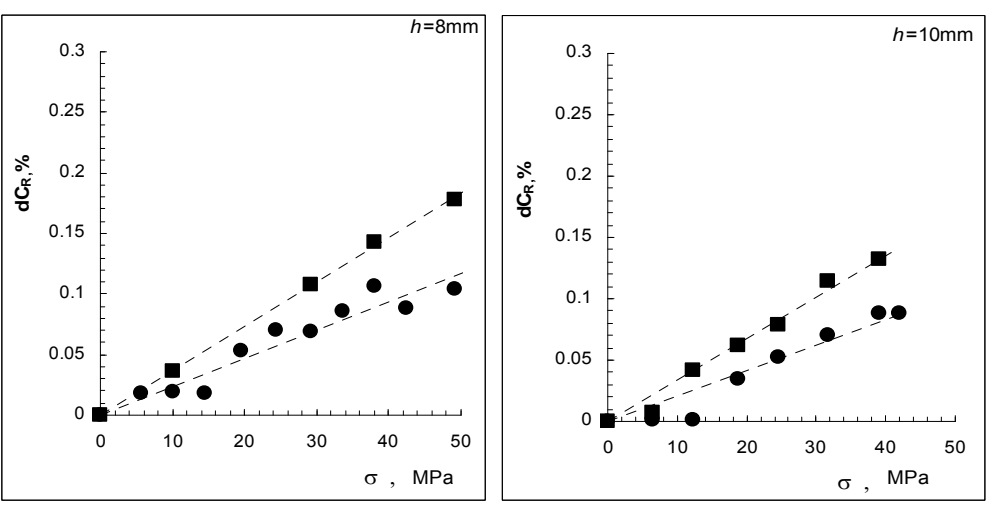

$\mathrm{b}$

c

Fig.4. Dependence of the relative velocity change on surface stress at $2 \mathrm{MHz}(\boldsymbol{\square})$ and $4 \mathrm{MHz}(\bullet)$ for $\mathbf{s a m p l e s ~ a ~}-h=5 \mathrm{~mm}, \mathrm{~b}-\boldsymbol{h}=\mathbf{8} \mathrm{mm}, \mathrm{c}-\boldsymbol{h}=10 \mathrm{~mm}$ 


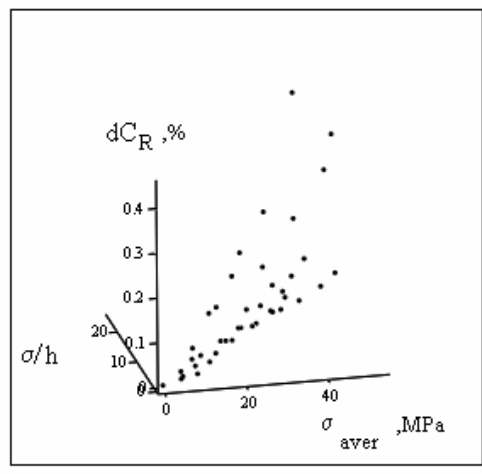

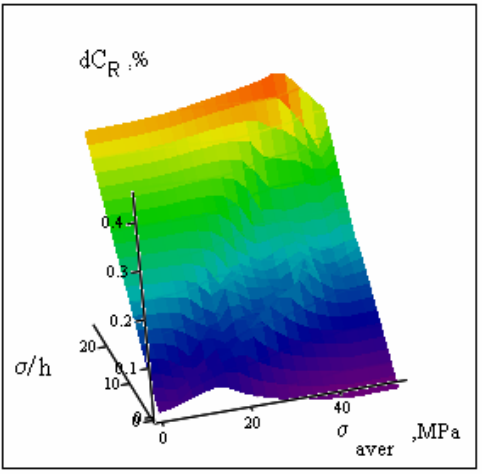

Fig.5. Variation of relative velocity change in dependence of stress gradient and average stress a - 3D scatter plot, $b$ - surface plot

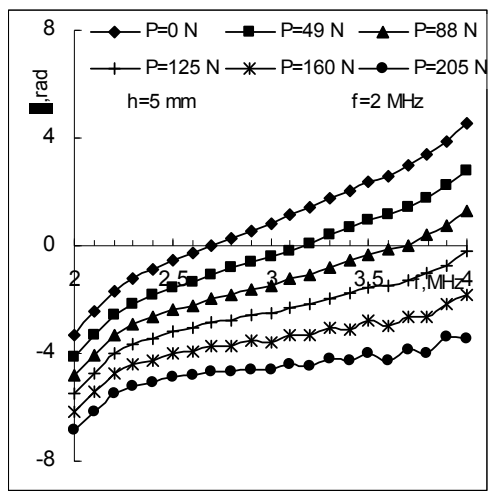

a

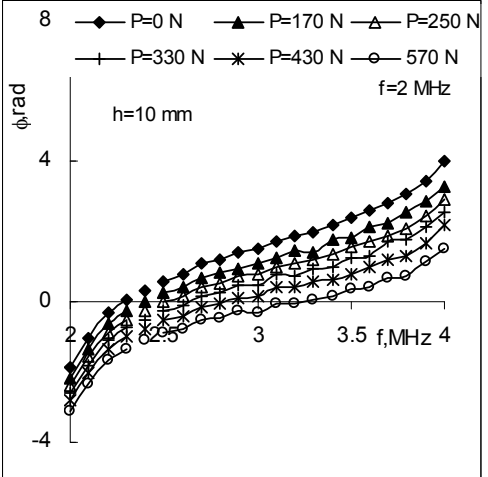

$\mathrm{c}$

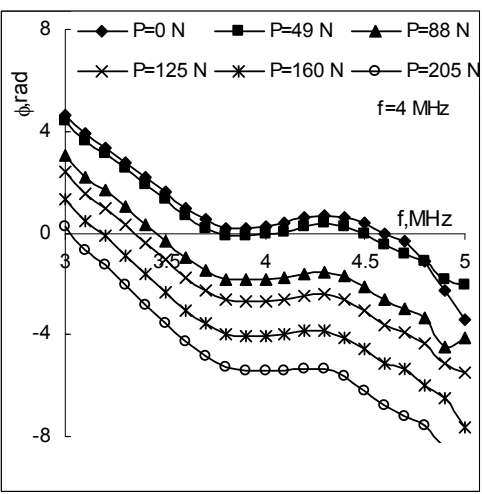

b

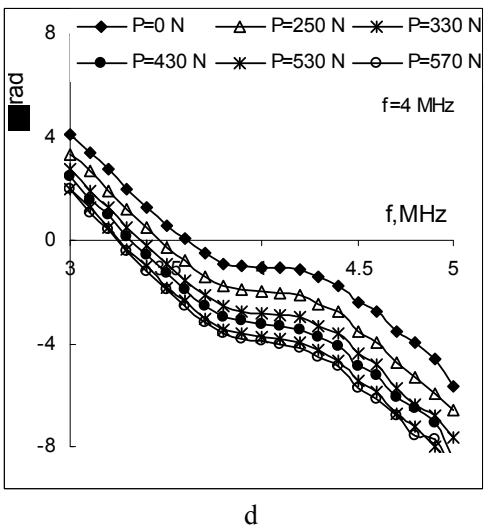

Fig.6. Phase spectra of ultrasonic signals a $-h=5 \mathrm{~mm}$, frequency $f=2 \mathrm{MHz} ; \mathrm{b}-\boldsymbol{h}=\mathbf{5} \mathrm{mm}, f=4 \mathrm{MHz} ; \mathrm{c}-\boldsymbol{h}=10 \mathrm{~mm}, f=2 \mathrm{MHz} ; \mathrm{d}-\boldsymbol{h}=10 \mathrm{~mm}$, 4 MHz.

\section{Phase spectra of ultrasonic signals}

The phase spectra of the ultrasonic signals obtained from samples with thicknesses $5 \mathrm{~mm}$ and $10 \mathrm{~mm}$ by the spectral analysis (Eq. 9) are presented in Fig. 6. The phases of the signals are better distinguished for specimens with a higher stress gradient.

\section{Cross spectral analysis}

The cross-spectrum phase $\Phi$ is essential in the frequency region from 1 to $5 \mathrm{MHz}$. The results shown in Fig. 7 concern the signals registered on the direction perpendicular to the bending moment. The stress-state guides the phase variation. The differences between the curves are considerable and are increased with the stress.
The slope of the phase can be used as the information parameter for a stress estimation.

\section{Influence of the stress gradient on the cross- spectrum phase}

The presence of the stress gradient affects an alteration of spectrum of the impulse wave and requires the signal processing [13]. The Fig. 8a and b are indicative of the phase shift. The higher stress gradient causes a greater slope. The changes are accumulated with the increase of the acoustical path. The slopes of the cross spectra phases obtained at $L 1$ and $L 2$ are marked consequently by squares and circles. The results at Fig.8a show higher values of the slopes at the $2 \mathrm{MHz}$ nominal frequency of the transducer. 
ISSN 1392-2114 ULTRAGARSAS (ULTRASOUND), Vol. 66, No. 1, 2011.

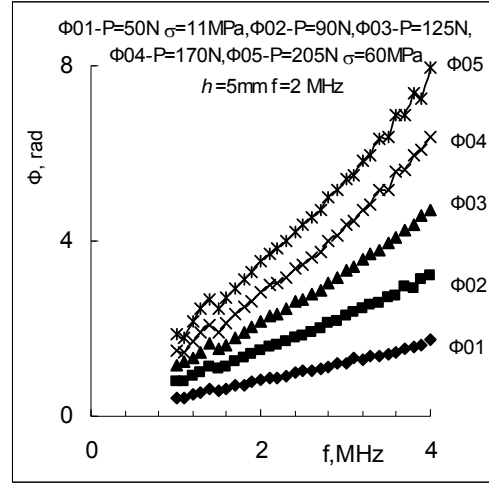

a

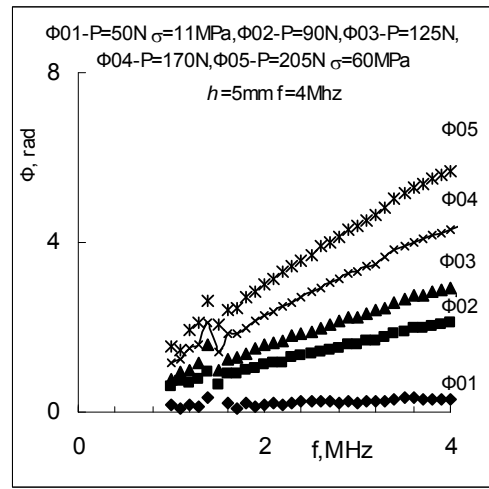

$\mathrm{b}$

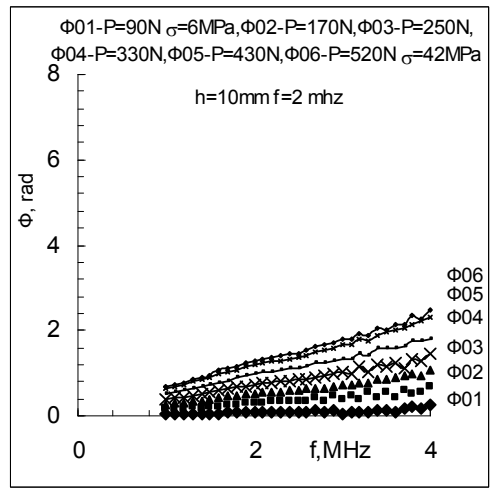

c

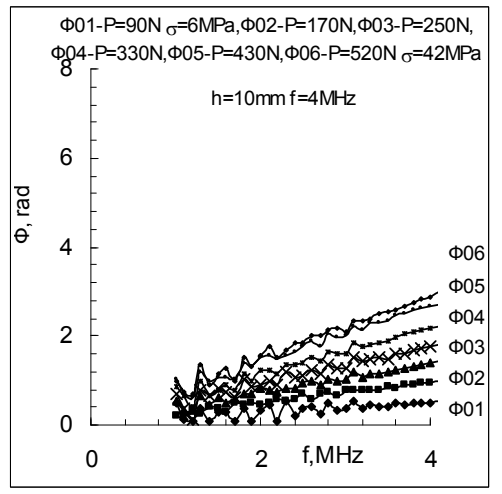

d

Fig.7. Dependence of cross-spectrum phase $\Phi$ on frequency $f$ : a sample with $h=5 \mathrm{~mm}-2 \mathrm{MHz}, \mathrm{b}-4 \mathrm{MHz}$; $\mathrm{c}$ - sample with $h=10$ mm - 2 MHz, d - 4 MHz.
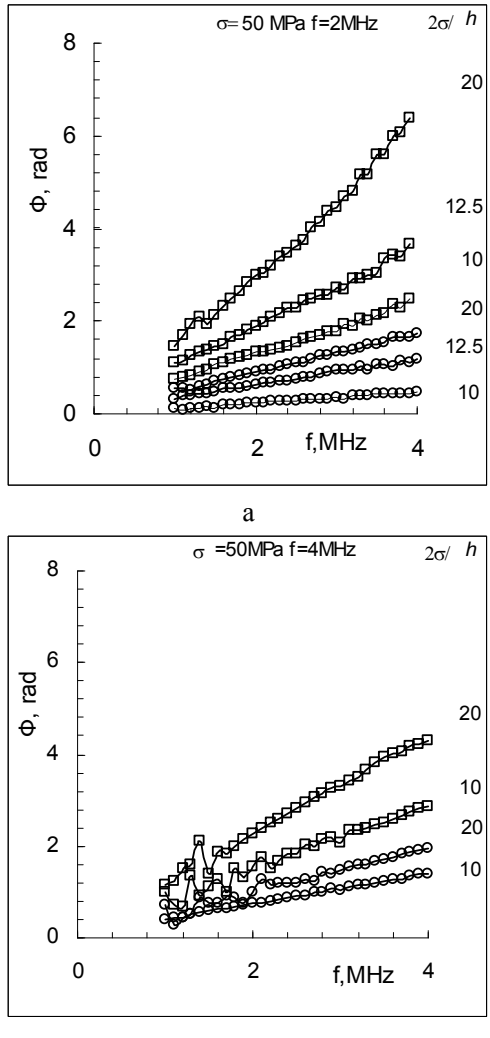

Fig.8. Stress gradient influence on the phase $\Phi$ a $-f=\mathbf{2 M H z}$, - $f=4 \mathrm{MHz}$.

\section{Anisotropy}

The materials used in the present work are taken from the serial production. The samples are made from low carbon steel sheets and have a small anisotropy of structure parameters. The measurements of ultrasonic velocity and registrations of ultrasonic impulses are carried out for different angles between the acoustical path and the bending moment as shown in Fig.9.

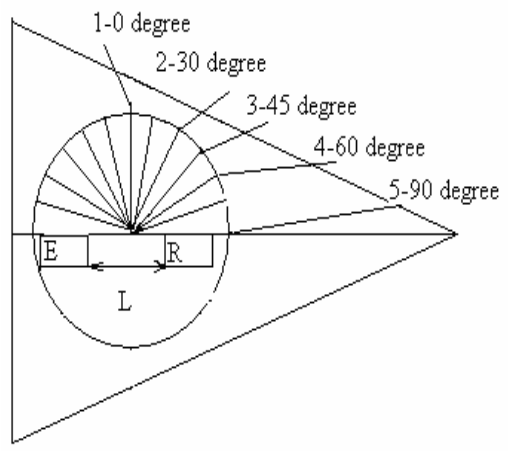

Fig.9. Scheme of anisotropy measurement

The relative change of surface wave velocity, measured in unstressed material in different directions with a step of 15 degrees is displayed in Fig. 10. The variations of CR are quite small and are less than of $0.2 \%$. The stress arouses the anisotropy of the acoustic properties. The signals of the unstressed and stressed materials, obtained in different directions are shown in Fig.11. The signals of 
the stressed samples appear after the reference signal (without a load) in direction №1. The signals coincide in direction № 2. This trend is more noticeable in the thinner material with a higher stress gradient.

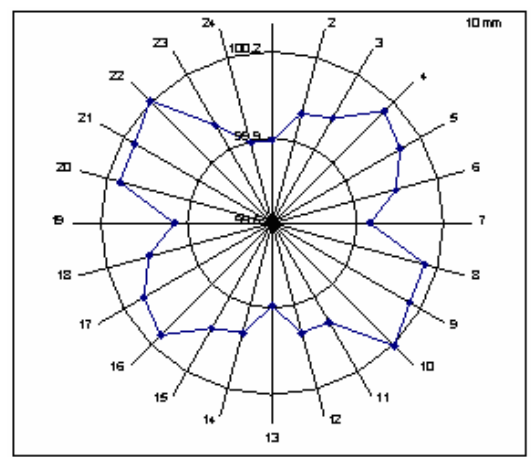

Fig.10. Variance of CR on directions

The Fig. 12a and $\mathrm{b}$ show the relative changes in the arrival time $\Delta \tau=\left(\tau-\tau_{0}\right) / \tau_{0}$, where $\tau_{0}$ is the arrival time of the unloaded materials for the samples with thicknesses 5 and $10 \mathrm{~mm}$. The velocities of the ultrasonic surface waves increase with the loads when the measurements are made in directions 3, 4 and 5 in Fig.9 и decreases in directions 1 and 2 . The stress gradient exalts this effect.

The variations of the signals are assessed by cross spectrum analysis. The impulses from the loaded samples are correlated with the reference signal.

The results about phase differences are shown in Fig. 13, 14, 15 and 16. The phases of cross spectra of signals obtained from samples with higher and smaller stress gradient at direction parallel toward the bending moment are presented in Fig.13. The Fig.14 presents the results at $30^{\circ}$ toward the bending moment. The slopes of the curves in Fig.13, the received from signals in the direction 1 decrease with the increasing loads. The phase shift grows with the increasing of the angle between the bending moment and the measurement line. Greater change is observed along a line perpendicular to the loading force at Fig.16.

The coefficient $S$ is the slope of the cross-spectrum phase $\Phi$ and is determined by (13).

$$
S=\frac{\Phi\left(f_{2}\right)-\Phi\left(f_{1}\right)}{f_{2}-f_{1}}
$$

where $f_{1,2}$ are 1 and $5 \mathrm{MHz}$.
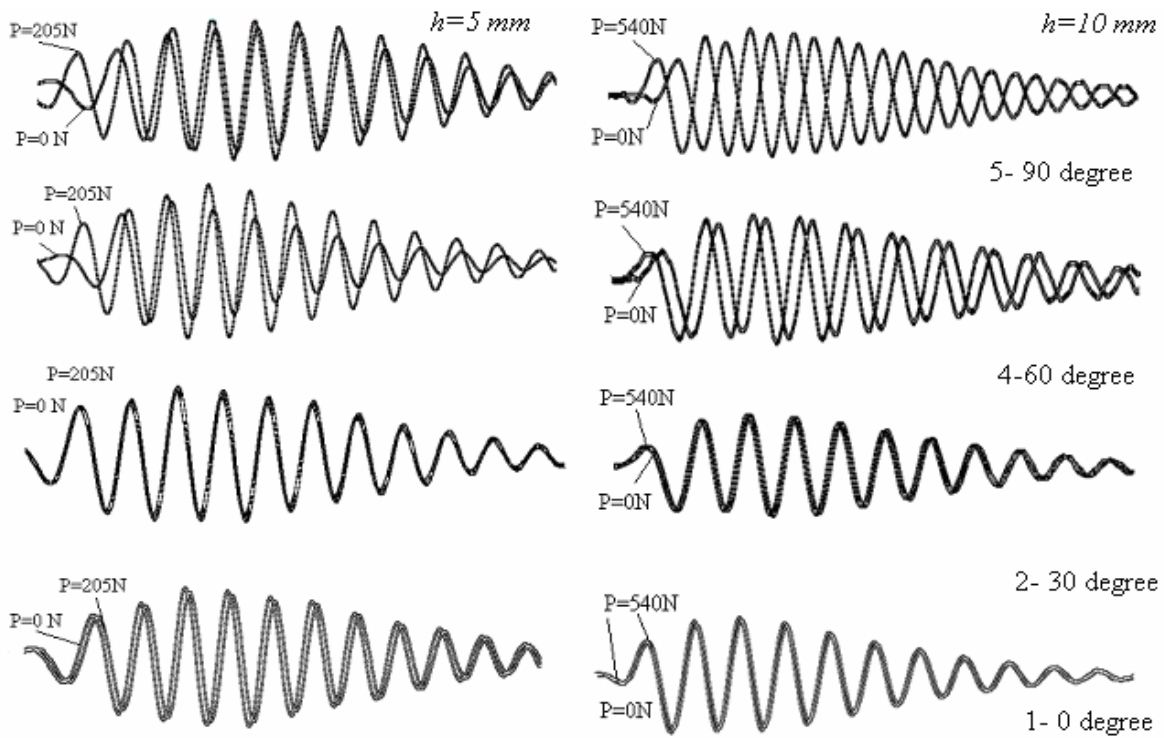

Fig.11. Signals in unstressed $(\mathrm{P}=\mathbf{0} \mathrm{N})$ and stressed samples with thicknesses $5 \mathrm{~mm}$ and $10 \mathrm{~mm}$ in different directions of the metal sheet
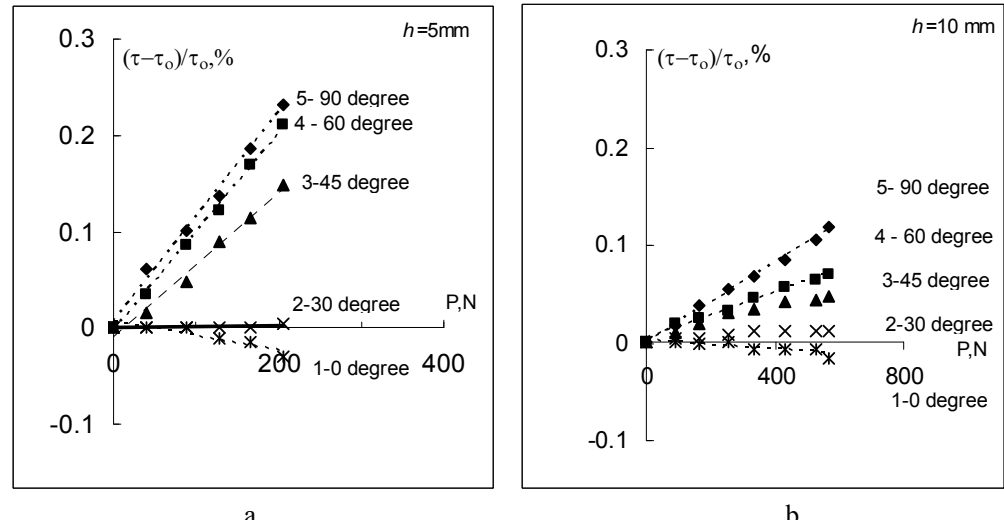

Fig.12. Dependence of the relative time $\Delta \tau / \tau$ on loads P: $\mathbf{a}-\boldsymbol{h}=\mathbf{5 m m}, \mathbf{b}-\boldsymbol{h}=\mathbf{1 0 m m}$ 
ISSN 1392-2114 ULTRAGARSAS (ULTRASOUND), Vol. 66, No. 1, 2011.

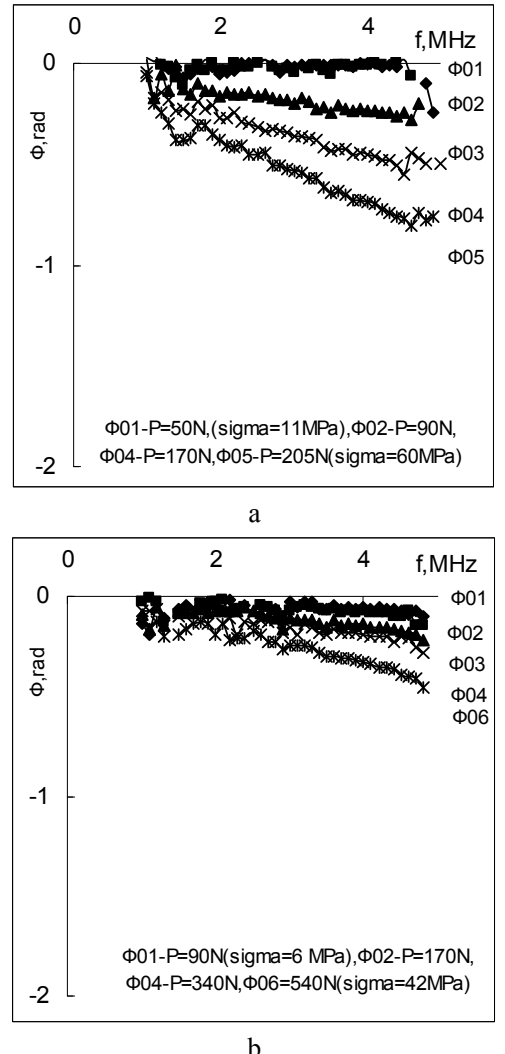

Fig.13. Phases of cross spectra of signals from samples at direction parallel toward the bending moment: a - high stress gradient $h=5 \mathrm{~mm}$; $b$ - small stress gradient $h=10 \mathrm{~mm}$

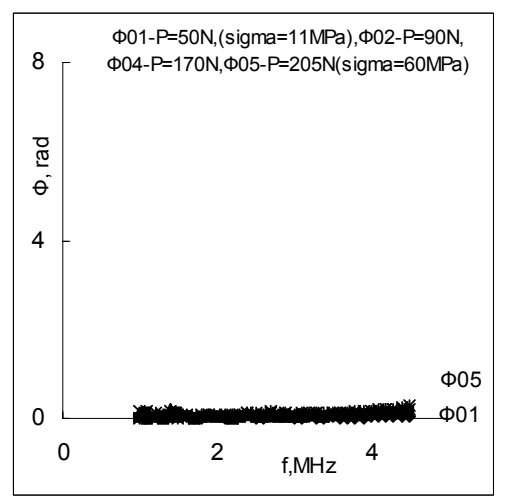

a

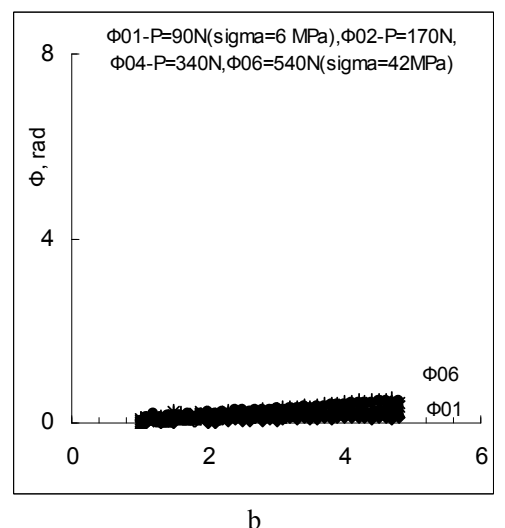

Fig.14. Phases of cross spectra at $\mathbf{3 0}$ degree toward the bending moment: a - high stress gradient, $b$ - small stress gradient

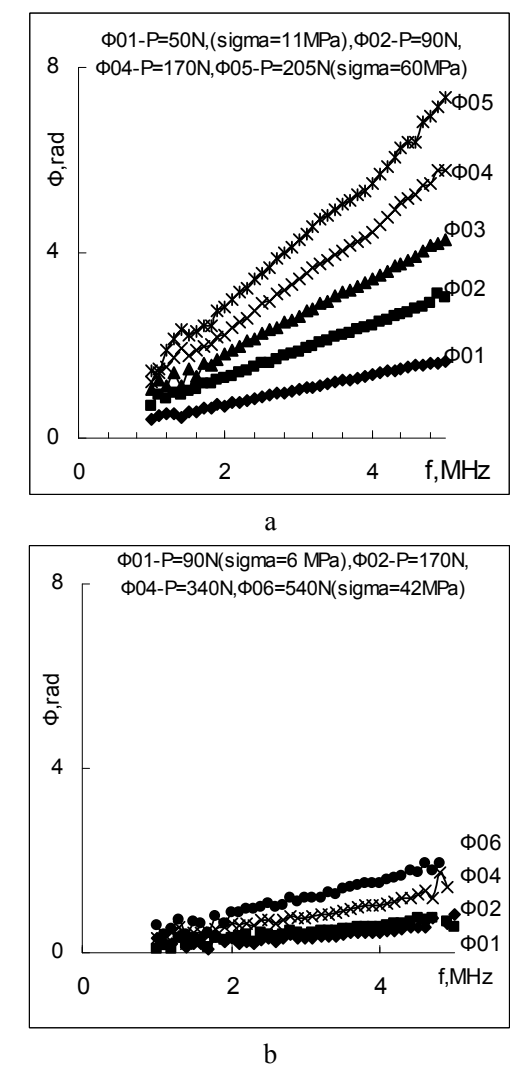

Fig.15. Phases of cross spectra obtained at 60 degree toward the bending moment: a - high stress gradient, b - small stress gradient

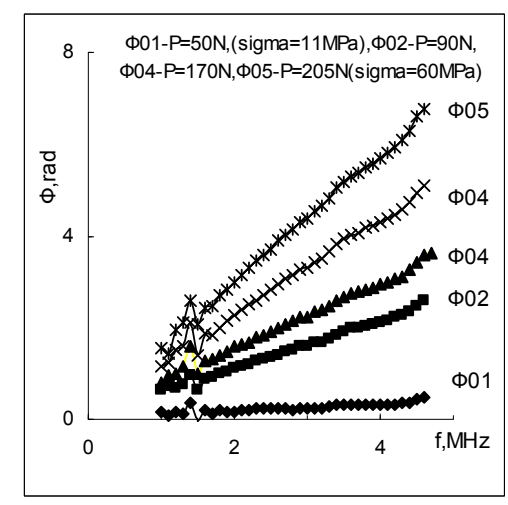

a

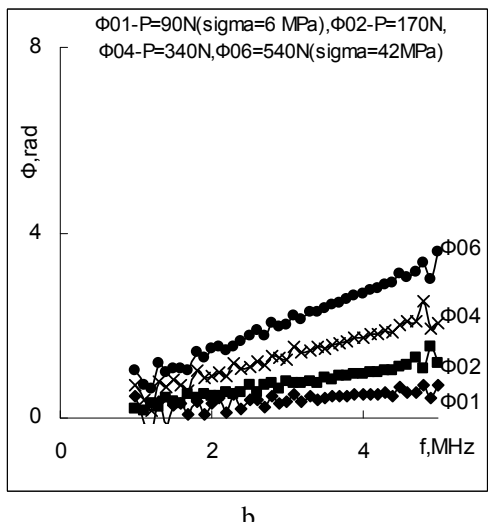

Fig.16. Phases of cross spectra at direction perpendicular toward the bending moment: a - high stress gradient, $b$ - small stress gradient 


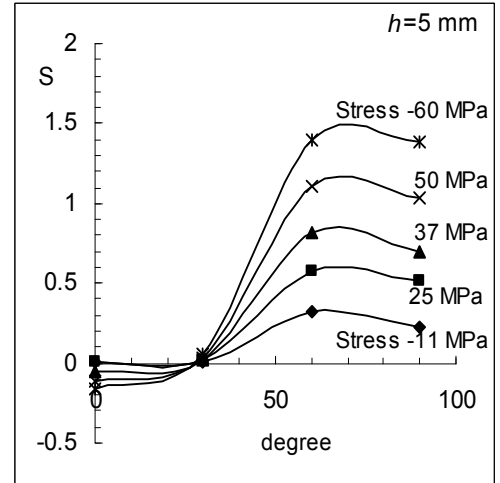

a

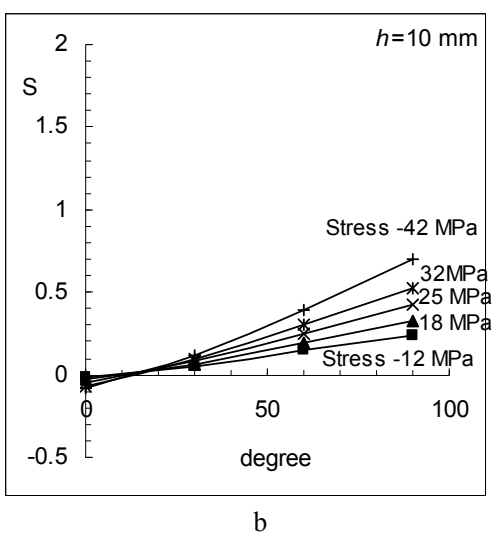

Fig.17. Dependence of slope versus degree of anisotropy measurement: a - high stress gradient $h=5 \mathrm{~mm}, b$ - small stress gradient $h=10 \mathrm{~mm}$.

The Fig. 17a and $\mathrm{b}$ show the variations of the slope versus direction of measurement. Greater stress causes larger values of slope. The phase slope can be used as a new information parameter for stress state estimation in materials.

\section{Conclusion}

The performed study shows the capability of the ultrasonic equipment to estimate the acoustical properties of elastically deformed materials. The small changes of the surface wave velocities in stressed materials are registered and measured. The use of a through transmission technique with emitting and receiving transducers for the Rayleigh waves and a digital ultrasonic flaw detector is perspective approach for stress-state evaluation of the constructions. The stress gives rise to anisotropy of the acoustical properties and leads to phase and group velocities variations. The spectrum and cross spectrum analysis of ultrasonic impulses are appropriate techniques for evaluation of the time delay of the signals in stressed materials. The slope of phase differences can be used as a good information parameter for recognition and assessment of a stress-state in materials.

\section{Acknowledgement}

The research was performed as a part of Project № 190/2010 with the Sofia University "St.Kliment Ohridski", Sofia, Bulgaria.

\section{References}

1. Bach F., Askegaard V. General stress-velocity expressions in acoustoelasticity. Exp Mech. 1978.

2. Guz A. N., Makhort F. G. The physical fundamentals of the ultrasonic nondestructive stress analysis of solids. Int. Appl. Mech.. 2000. Vol. 36. No. 9. P.1119-1149.

3. Guz A. N., Makhort F. G. Acousto electro magneto elasticity. Naukova dumka. (ISBN 5-12-009322-1). 1988. Vol. 3. P.288 (in Russian).

4. Nikitina N. Ye. Non-destructive evaluation of stressed states of solids with the help of acoustoelastic effect. ISSN 1392-2114. Ultragarsas.1999. Nr. 2(32).

5. Hirao M., Fukuoka H., Hori K. Acoustoelastic effect of Rayleigh surface wave in isotropic material. ASME J. Appl. Mech. 1981. Vol. 48. P.119-124.

6. Kline R., Jiang, L. Using ultrasonic Rayleigh wave dispersion to characterize residual stresses. In: Thompson, D.O., Chimenti,D.E. (Eds.), Review of Progress in QNDE. Plenum Press, New York, USA. 1996. P.1629-1636.

7. Husson D., Kino G. S. A perturbation theory for acoustoelastic effects. J. Appl. Phys. 1982. Vol.53 (11).P. 7250-7258.

8. Rajagopal P., Balasubramaniam Kr., Maddu Sh., Krishnamurthy C.V. A new approach to inversion of surface wave dispersion relation for determination of depth distribution of non-uniform stresses in elastic materials, International Journal of Solids and Structures. 2005 Vol.42. P. 789-803.

9. Si-Chaib M. O, Menad S, Djelouah H, Bocquet M. An ultrasound method for the acoustoelastic evaluation of simple bending stresses. NDT E Int. 2001. Vol.34. P.521-9.

10. Landa M, Plesek J. Ultrasonic techniques for non destructive evaluation of internal stresses. 15th CWNDT. Roma. 2000.

11. Lu W. Y., Dike J. J., Peng L.W., Wang J. Stress evaluation and model validation, Using Laser Ultrasonics Materials Chemistry Department, Sandia National Laboratories, Livermore.1999.

12. Ivanova Y., Telbizov G. The possibility for stress evaluation using the ultrasonic waves, In: Sci. Announces of Sci. Tech. Union Mech. Eng. (ISSN 1310-3946). Year XV. 2008. No. 2 (105). P.185 -190 (In Bulgarian).

13. Partalin T., Mihovski I., Ivanova Y. Propagation of ultrasonic surface waves in Materials subjected to bending, bulg. Conference "Metal Science and New Materials' 2008", Institute of Metal Sciences-Bulgarian Academy of Sciences, 4-5 December 2008. P.2530. (in Bulgarian).

14. Kissyov S. Strength of materials. Technique, S. 1978 (in Bulgarian).

15. Guide to OPKUD and OPBOX- Ultrasonic Testing Units-Technical Data, http://www.optel.pl.

16. Viktorov A., Rayleigh and Lamb waves, Physical Theory and Application, Plenum Press, New York. 1967. P.154.

17. Nondestructive testing. Handbook. 2007. Vol. 4. Moscow. Publ. House "Spectr" (in Russian).

18. Oppenheim A. V. and all. Signals and Systems, Pearson Education 1998.

19. Hartmann D. Cross Spectrum Analysis, ATM 552 Notes, Section 6c. P.157. Internet. 
ISSN 1392-2114 ULTRAGARSAS (ULTRASOUND), Vol. 66, No. 1, 2011.

20. Zywicki D. Advanced signal processing methods applied to engineering analysis of seismic surface waves, $\mathrm{PhD}$ Dissertation. Georgia Institute of Technology. 1999.

21. Douglas Maraun. Outlining cross spectral analysis. Physics Institute, University of Potsdam. In internet.

22. Mallett R., Mudge P. J, Gan T-H and Balachandran W. Analysis of cross-correlation and wavelet de-noising for the reduction of the effects of dispersion in long-range ultrasonic testing, Insight. 2007. Vol. 49. No.6.
Y. Ivanova, T. Partalin

Valcuotų lakštų ịtempių būsenos tyrimas ultragarsiniais metodais

\section{Reziumè}

Itempiu būsenai kietuosiuose kūnuose tirti buvo panaudotas ultragarsas. Tuo tikslu ant valcuoto anglinio plieno lakštų paviršiaus ivvairiomis kryptimis buvo matuojamas paviršinių ultragarso bangų greitis. Signalai buvo apdorojami ir ittempių būsena analizuojama panaudotas kryžminio spektro analizès metodu.

Pateikta spaudai 20110314 